\title{
Geoff Rashbrooke
}

\section{Decumulation 101 the basics of drawing down capital in}

retirement

\section{Introduction}

\section{Decumulation in the retirement income context is the using}

up of retirement savings by way of drawing out regular income - for example, a fixed amount each month. It's the converse of accumulating retirement savings while in paid work by regularly putting money aside. And return on investment plays its part in both: in the accumulation phase it enhances the amount saved; in the decumulation phase it enhances the regular amount that can be paid out.
The first question is whether decumulation is something that actually needs any policy attention. Since the answer to that question here is a qualified yes, the next part of this article outlines a number of decumulation methods, considering such matters as cost, risk and flexibility. The desirability of any form of decumulation to individuals will naturally vary according to their preferences in respect of those points. The article concludes by positing some public good components in respect of each decumulation method, and setting out some possible government interventions in response.
Overall, the object of the article is to introduce readers to the policy questions at a fairly high level, and there will be no in-depth research quoted; academic references are unashamedly in short supply. Readers are left to identify research possibilities for themselves.

\section{Relevance}

For most people, life experience up to retirement does not teach how to manage retirement savings assets for financial support thereafter. Investment of savings is mostly left to experts. At best, many aim to live on the income generated by those assets after retirement, and leave the assets for their heirs. At worst they spend the lot, which may have its attractions but doesn't usually result in anything sustaining for the rest of life.

The lack of acquired competence in managing financial assets for income could be seen as already sufficient reason for paying attention to decumulation policy. But provision of regular income is only one use of retirement savings, and a number of conflicting objectives need to be reconciled. Some questions individuals need to ask themselves as they withdraw from paid work are: 
- What debts would it be sensible to pay off, so as to save making repayments out of my retirement income?

- What amount of assets do I want to hold as 'rainy day' money against shocks (such as needing urgent medical treatment not available quickly in the public health system) or some planned major expenditure, such as travel or replacing a car?

- Is there some bequest I want to make?

- Apart from my 'retirement savings' assets, what other assets do I have: for example, a house?

- Is all the income generated from my assets available to be spent, or do I want to put some aside to protect the real value of my intended bequests? assessment may lead to the conclusion that decumulation is not relevant to them: access to some financial assets can often make a significant difference to welfare after retirement, providing resilience to financial shocks. For those more financially advantaged the assessment is not straightforward. One problem is that the income one might generate from decumulating some savings can be hard to quantify. (The Sorted website of the Commission for Financial Literacy and Retirement Income could help here, but would need to be able to reference and quantify decumulation products.)

Nonetheless, decumulation products have the potential to be very useful, particularly for those with minimal bequest intentions. And, without wanting to sound excessively paternalistic, it may

\section{Although regulation of advisers has improved over the last decade, there is still no real basis on which to assess who will do a good job and who will not.}

These questions lead to identification of the assets one wants to hold on to, and for how long. In turn this leads to determination of how much, if any, will be available to be run down through decumulation to provide additional income on top of:

- investment income from the assets planned to be retained (rather than run down), including rents;

- New Zealand Superannuation when eligible;

- any private pension;

- earnings from continued paid workforce participation, including self-employment.

There may well be trade-offs needed between the level of total regular income one would like to have and how much one wants to retain for bequests and/or rainy day money (and hence not available for decumulation).

For those with little retirement savings and no freehold house, such rent in this context) and no tax on any drawdown of capital.

\section{Financial adviser as manager}

This is employing a person on an ongoing basis to manage the drawdown of retirement assets. This seems ideal. There should after all be a number of people who have an excellent knowledge of the financial products on the market, and who also understand how to communicate and engage with their clients in order to explain the risks and rewards of different scenarios.

There are, however, two large problems with entrusting retirement wealth to an adviser. One is cost. On a personto-person basis, if you have moderate wealth then it is very expensive relative to assets to engage a financial adviser other than short-term, and not always just then. Commission-based remuneration disguises this cost, but does not align the interests of the adviser and the client.

The other problem is competence. It has been said of financial advisers that those who can, work on their own account, and those who can't, advise. Whether one agrees with that or not, what is inescapable is that a poor adviser can cost clients dearly through their naivety or inability, let alone any fraudulent behaviour. Although regulation of advisers has improved over the last decade, there is still no real basis on which to assess who will do a good job and who will not. Hence, although there are doubtless some very good practitioners and a number who are reasonably competent, getting a financial manager who is not up to scratch puts at risk the whole of one's savings.

There is little scope to reduce the cost of direct, ongoing financial advice. One could observe that on average a financial adviser is less likely to do damage to a client's savings than the client themselves, and that this has value. How much, however, is disputable. And adviser competence issues remain: poor performance has catastrophic and unrecoverable effects.

\section{The lifetime annuity}

This is the most traditional form of decumulation. An insurer, by pooling mortality risk over a sufficiently large number of annuitants, can offer to provide 
a fixed monthly amount for life in return for a lump sum. The insurer also effectively provides a guaranteed investment return. The working of an annuity is not, however, at all transparent. Determining how much monthly payment can be made for a given lump sum depends on projecting annuitant mortality (rather lighter than population mortality), investment return and expenses, and incorporating a profit margin for the cost of the capital held for solvency purposes. So annuities remove mortality, investment and expense risk in respect to the payments the annuitant is due to receive, but in doing this are more expensive to provide than a simple analysis would suggest.

On the demand side, potential annuity purchasers have difficulty with the prospect that if they die early, no refund of the unexpended part of the purchase price is available. One can try to explain that this is the result of riskpooling and someone has to pay for those who live longer than average, but the downside risk does predominate. And, of course, there is no flexibility, no facility to change the arrangement to cope with an unexpected call on funds.

In terms of taxation, the aim should be neutrality for the individual. It is possible, although complex, for tax to be attributed to individuals by reference to the balance remaining of their purchase price, plus investment return credited to date, net of all expenses, plus the share of fall-in from deceased annuitants. Since it would be impossible to set prices based on projecting future individual tax rates, neutrality requires the insurer to pay no tax on its annuity business (other than profit, as it emerges) and the annuitants to be taxed directly on attributed investment income each year.

A useful approximation in place of annual attribution is to identify one half of an annuity payment as income: this may be acceptable on the basis that, very broadly, half of the total payout over an average lifetime will be investment income and half will be return of capital. (The precise split depends on the level of investment income earned.) Note that this approximation takes relatively more from those who live longer on average compared to those who die early.

\section{Pooled annuity funds}

These are an attempt to reduce the cost (i.e. improve the annuity payout) of the lifetime annuity. The administrator operates a pooled fund for mortality and investment risk, but does not provide any guarantees. The initial annuity is estimated based on applicable mortality and anticipated net investment return (and expenses), but annuity amounts may be reset each year based on actual experience. The administrator profit is usually derived from the investment activity.

Normally, lifetime annuity pricing is based on the best expected longevity (unless annuitisation is compulsory). Pooled annuity funds are voluntary, but could be segregated and, by making use of insurance risk assessment processes, expense risk), the drawdown pension works on an individual approach. There are variations, but the basic approach is for a regular payout to be calculated based on the amount deposited, expected investment return and expenses, and the pensioner's preferred payment period. Operationally, a pension account is established, investment return credited, and pension payments and expenses debited. Tax is - or should be - paid by the pensioner on the net investment income credited. When no money is left, payments cease. If the pensioner dies before running out of funds the balance goes to the heirs.

Were the period set to life expectancy - the average period a person is expected to live - then, assuming investment returns and expenses match the estimates,

\section{Were the period set to life expectancy - the average period a person is expected to live - then, assuming investment returns and expenses match the estimates, half the pensioners will run out of funds before they die.}

pool those with poorer longevity prospects. However, attracting enough people to make this viable on a voluntary basis appears difficult. Indeed, while theoretically attractive, pooled annuity funds appear to have obtained even less traction than life annuities. Likely reasons include the downside risk of loss of some capital outweighing the continued payment, and absence of a tradition of such funds. Obtaining neutral tax treatment again has the same issues as with the lifetime annuity. The only real advantage of pooled annuity funds over lifetime annuities is the absence of a requirement for regulatory capital, and therefore potentially higher annuities for the same purchase price.

\section{Drawdown 'pension'}

While the lifetime annuity pools mortality and investment risk (and half the pensioners will run out of funds before they die. For this reason a longer payment period may be favoured: for example, to the point where $70-75 \%$ of people will have died. Conversely, people who consider they are in poor health, or who have other resources for later in life, may prefer a period less than the average lifespan.

Because funds are held in individual accounts the facility of lump sum withdrawals can be provided, with a reset of the monthly pension. The administrator, however, will need to charge those who avail themselves of this appropriately, since not only are there administrative costs, but also implications for investment policy if higher liquidity may be needed.

Costs of the pension will include investment charges and administration, as well as a profit charge (although little 
regulatory capital is needed), basically for providing an investment service. Drawdown pension arrangements can offer a variety of investment allocation strategies, particularly for longer planned drawdown periods; the deduction from gross income for investment charges (and profit) should be transparent, but may not always be so.

While the greater flexibility and capital protection are attractive, drawdown accounts can be depleted for the longerlived, potentially giving rise to a nonanticipated fall in living standards. Poor investment returns compared to those anticipated in setting the drawdown
Drawdown 'pension' or term annuity plus deferred annuity

From the discussion of decumulation methods so far, it will be noted that drawdown pensions have the greatest 'market' appeal due to flexibility, but do carry the risk of reaching a certain point and running out of income. Term annuities have the same drawback. This suggests combining a drawdown pension arrangement or term annuity with a deferred annuity - that is, a lifetime annuity which doesn't commence until age 80 , for example, or even age 85 - in order that there is a guarantee of income in the later years if one survives past the

\section{... many people are not well equipped to manage retirement assets for decumulation purposes themselves; nor is it reasonable to expect them to upskill (assuming ability to do so).}

amount may curtail the actual period of receipt (although the converse, better returns, will extend it).

\section{Term annuity}

A term annuity is a series of regular payments for a fixed term. Unlike a lifetime annuity, payment continues if the annuitant dies before the end of the fixed term. Pricing, therefore, does not need to include mortality projections. The advantage of a term annuity over a drawdown pension is that the payout amounts are known: there is effectively an investment guarantee. Conversely, there is no flexibility in terms of access to lump sums. And, like drawdown, the payout may well stop before death, the likelihood of that depending on the term chosen.

Regulation requires ensuring adequate reserving, plus regulatory capital for the investment guarantee. A term annuity is likely, therefore, to be less than a comparable drawdown pension. Tax on investment return has the same issues as for a lifetime annuity. drawdown period or comes to the end of the term annuity period.

A deferred annuity requires rather less regulatory capital in relation to mortality risk than an immediate annuity, because the guarantee period is quite a lot shorter. There does, of course, need to be regulation to ensure adequate reserves are held and that profits are not anticipated before they are earned. Nonetheless, deferred annuities are less capitalintensive than full lifetime annuities, and should be more easily presented as direct insurance against living too long.

Purchase of a deferred annuity need not be associated with obtaining a drawdown pension or term annuity, but put together they offer the opportunity for retirement planning by harmonising the regular income from drawdown or fixed-term annuity and the deferred annuity (although there could be a hiatus if the drawdown funds run out before the deferred annuity kicks in). Note that the neutral tax treatment of deferred annuities presents the same issues as for immediate lifetime annuities

\section{Home equity conversion}

Home equity conversion is not strictly speaking a decumulation option itself, but the funds made available from releasing equity in the home can then be converted into an income stream, in one of the ways set out above. The most common form of home equity release, the reverse mortgage, advances money on the security of the home. Compound interest is payable on the advance, but the owner retains full entitlement to remain in the home. The advance and accumulated interest are recuperated when the owner dies or moves out, whichever occurs first.

Reverse mortgage contracts usually have a no negative equity guarantee: that is, the total recoverable cannot exceed the current value of the house after expenses of sale. For this reason the maximum proportion of value that can be released takes into account mortality (including mortality improvement), likely interest charge, and likely increase in house prices for the kind of property in question.

It is understood that paying an advance as regular income has been considered by local home equity providers. There is no obvious reason why such providers could not offer a drawdown facility, and/ or make deferred annuities available through a registered insurer.

\section{Public good issues}

The argument here is that welfare in later life would be improved were greater use made of decumulation products. As discussed earlier, many people are not well equipped to manage retirement assets for decumulation purposes themselves; nor is it reasonable to expect them to upskill (assuming ability to do so). And having assets assigned to decumulation will also offer protection against fraud and loss of cognitive ability.

The decumulation products described above are, however, either not widely available or in apparently low demand. In this situation, a three-pronged policy response in respect of education, standardisation and regulation (including tax) would do the following: 
Education would explain the advantages of decumulation, help people identify what assets (if any) could be used for decumulation, and identify the pros and cons of different options according to personal preferences in respect of risk, flexibility and cost.

Standardisation would be desirable in order that people not become bewildered by choice, and would help keep education initiatives focused. A comprehensive but limited option set can be a useful nudge as to what people should be looking at. It also enhances competition, as comparison of different providers is considerably simplified. Once the basics have been in place for a while, more sophistication can be introduced later.

Regulation is required to give confidence that, where a decumulation product provides guarantees, the purchaser can be confident that, in all reasonably foreseeable circumstances, those promises will be kept. It provides not only for reporting but also for monitoring and enforcement, where it is not reasonable to expect most clients to have the adequate skill or interest to do this themselves, and there is no gain for third parties to step in. Tax treatment would be neutral across options to avoid tax arbitrage affecting choice between products. Some concessional treatment could, however, be considered on a cost-benefit assessment where any particular decumulation product benefits the whole community.

So what might this policy framework mean in respect of each decumulation method listed above?

\section{Financial adviser as manager}

What is being considered here is having someone manage the whole decumulation process through ongoing asset management, not just giving advice on decumulation products such as lifetime annuities, etc. One might consider that, as only the very wealthy would find such an approach cost-effective, no intervention is needed. However, the very wealthy are not necessarily all financially astute, and in any case some with lesser wealth might want to consider the possibility. For monitoring and regulation purposes, then, a policy option would be to maintain a register of qualified decumulation managers. Applicants would need to demonstrate fitness for the role, and to file reports on their activities and performance on behalf of their decumulation clients, with the registrar given a proactive role in monitoring. The aim would be to identify
Ultimately, however, it is difficult to see how insurers can obtain a required return on capital without compulsory annuitisation, as there was in the UK until very recently. For example, government could require annuitisation of the subsidised element of KiwiSaver entitlements. If that is a step too far, and there are good arguments either way, then arguably there becomes a role for government to establish a state-owned annuity corporation to provide lifetime annuities, on market-failure grounds. Were this to occur, however, there will still be need for best-practice regulation

\section{The existence of properly costed and managed deferred annuities would allow retirees to decumulate initially using drawdown pensions and/or term annuities, protecting themselves against early death}

poor performance before it did too much damage; however, a performance guarantee fund, with levies tied to risk profiles, would also provide assurance to potential clients. Significant penalties for carrying out this business unregistered would be necessary to deter the unethical, and protect the brand. With this structure in place, education measures would be straightforward: describe the register, set out the requirements placed on those registered, and give an indication as to likely annual costs.

\section{Lifetime annuity}

While the benefits of these are appreciated by risk professionals, there is a corresponding lack of appreciation by laypeople. Education could assist, but there will remain distrust of insurers due to the opaque nature of the product. This can be addressed in part by improved regulation, including a review of currently applicable tax rules (also opaque); it would be helpful if tax treatment was demonstrably neutral. (including for solvency capital) and best design practice: ideally automatic cost of living indexation, or at least some proxy such as annual $2 \%$ increases (i.e. at the broad inflation target rate).

Education initiatives to explain annuities, particularly the guarantees, would only be sensible if these other steps are taken - i.e. tax neutrality, sound regulation, and either some compulsion or the imprimatur of a government entity.

\section{Drawdown 'pension'}

This option is the most transparent and education can focus on how it works without too much difficulty. The key policy action is standardisation. What would be truly useful would be to require each KiwiSaver default provider to offer a drawdown pension arrangement with the following characteristics:

- a standard pension based on Statistics New Zealand population best-estimate mortality projections to last five years past life expectancy, 
and investment return based on the experience of the provider's default portfolio, net of expenses;

- a 'high' pension to last until five years before life expectancy;

- calculation of pension to allow for automatic increases of $2 \%$ per annum;

- access to capital on full cost recovery, including a liquidity charge; and

- opportunity to reset - subject to a minimum monthly pension amount, since costs are similar per payment.

Regulation would fall under current KiwiSaver rules and scrutiny. While other forms of drawdown need not necessarily be barred, some form of branding should be used to establish the primacy of the standard versions, and other forms would need to be brought under KiwiSaver legislation.

\section{Term annuity}

This is in essence a bank product, since management principally concerns credit risk. One might consider requiring banks to offer a range of terms $-5,10,15$ years - in return for government education initiatives so that retirees include these as options to consider. Certainly it would help retirees (and their advisers) to have an indication as to what they could obtain in this fashion.

\section{Pooled annuity funds}

While discussion of decumulation would have been incomplete without mentioning these, there does not seem any compelling reason to devote any further consideration to them here.

\section{Drawdown 'pension' or term annuity plus deferred annuity}

The deferred annuity can be seen as the missing piece of the puzzle, since it provides insurance against living longer than expected. One obvious drawback, however, is that by providing an income source, it could constrain access to welfare benefits such as the residential care subsidy. Certainly, where means testing focuses on income and excludes capital, treating a capital element as income would be disadvantageous.

These considerations suggest that a concessional tax treatment for deferred annuities might have direct welfare benefit savings, as well as being welfareenhancing in the wider sense. It would clearly be essential to ring-fence deferred annuities from other forms of annuity, and to have appropriate prudential regulation.

Whether or not the market-failure argument to have government offer lifetime annuities is accepted, the argument becomes stronger for deferred annuities, picking up the role of government as insurer of last resort. Whether this role could extend to inflation indexing is another point for investigation. Certainly the absence of any facility to obtain a good annuity product was regarded as an argument for being able to choose to defer New Zealand Superannuation payments.

The existence of properly costed and managed deferred annuities would allow retirees to decumulate initially using drawdown pensions and/or term annuities, protecting themselves against early death, and then have continued income if they survive past the point when the other two run out. The balance to put into a deferred annuity compared to that for drawdown or fixed term could be set according to preferences for continuing income: some might wish to target a level income; others a lower income in the deferral period, perhaps because they expect to be less active. The Sorted website would be very suitable in helping people investigate this for themselves, and the Commission for Financial Literacy and Retirement Income could no doubt run effective education campaigns to assist more comprehensive retirement income planning.

\section{Home equity release}

Education here would have two aspects: letting people know that they have an income option through using one of the main decumulation approaches; and making sure that the costs of home equity release are understood. The dominance of one provider in the past has handicapped proper competition, with the profit margins - to the extent that these can be estimated - looking very high compared to those in more competitive jurisdictions, such as the UK. Again, it is moot whether the government needs to introduce competition by establishing its own provider, as it did with Kiwibank; a problem, however, could be finding enough credit. Were the government to get involved, it could reasonably require that proceeds be taken as drawdown or fixed-term plus deferred annuity - i.e. focus on income provision.

\section{Recommendations}

Provision of lifetime annuities has collapsed and no immediate replacement has occurred. Some government intervention could assist the development of the most promising option, the drawdown pension. Standardisation is strongly recommended to ensure good understanding through education initiatives and meaningful competition, leaving room to relax strictures when the method has better public understanding.

Deferred annuity provision is the natural complement to drawdown. Some people may not want that insurance, but for those who do there are currently no market products. Again, government intervention, including public education, appears necessary; in time this should lead to opportunity for private providers. 